\title{
Covid-19 - Lockdown Efficacy in Different Countries
}

\author{
Shaik Sarwar Allam ${ }^{1}$, Dr. Swaroopa Chakole ${ }^{2}$ \\ ${ }^{1}$ Intern, Dept. of Community Medicine, Jawaharlal Nehru Medical College, Datta Meghe Institute of Medical \\ Sciences (Deemed to be University), Sawangi (Meghe), Wardha-442001, Maharashtra, India \\ ${ }^{2}$ Professor, Dept. of Community Medicine, Jawaharlal Nehru Medical College, DattaMeghe Institute of Medical \\ Sciences (Deemed to be University), Sawangi (Meghe), Wardha-442001, Maharashtra, India \\ Email: ${ }^{1}$ shaiksarwarallam@yahoo.com, ${ }^{2}$ drswaroopachakole@ gmail.com
}

Corresponding author's name and address: Dr. Swaroopa Chakole, Department of Community Medicine, Acharya Vinoba Bhave Rural Hospital, Datta Meghe Institute of Medical Sciences (DU).

Corresponding author's email id: $\underline{\text { drswaroopachakole@gmail.com }}$

Type of Article: Review

Conflict of Interest: None

Funding: DMIMS

Ethical Approval: IEC, DMIMS, Wardha.

\begin{abstract}
BACKGROUND

COVID-19 or coronavirus disease 2019 is seriously affecting the day-to-day life of all the people on the planet. To add to the woes more virulent mutated strain has been discovered and more study is being carried out.

\section{SUMMARY}

Treating COVID-19 is a challenge in itself as the containment is tough due to high spreading capacity and its deadly nature. The initial phase of the disease has taken aback almost all the countries due to its high virulent nature. Therefore, blanket measures like lockdown and physical distancing were adopted by different countries after the COVID-19 was declared as pandemic by WHO. Various studies on its efficacy has been done and more needs to be done in order to obtain holistic approach.

\section{CONCLUSION}

Lockdown as a preventive measure during COVID-19 pandemic was proved to be effective in containing the viral spread. But only lockdown was not the only factor and other NPI's was supplementing the containment measures. More study across the nation's border is needed so that greater clarity can emerge from the datasheet.
\end{abstract}

KEYWORD:COVID-19, LOCKDOWN EFFICACY, MUTATION, NPI, PREVENTIVE MEASURE, INFODEMIC.

\section{INTRODUCTION}

COVID-19 or the coronavirus disease 2019 as named by the researchers has affected almost every individual inhabitant of the planet earth directly or indirectly. The Wuhan city of the Hubei province in China saw the first few cases which grew rapidly and initially it was thought as unknown cases of pneumonia. But later it was found out that the strain of the virus belongs to the SARS-COV family and named novel coronavirus (SARS-COV2)(1). Since then, it spread through Europe, America and all other continents which are populated. As of December 28, 2020,80,895,693 infected cases of
COVID-19

have been registered from more than two hundred countries and among them 1,767,043 have died due to COVID-19 related complications(2). Extremely virulent nature and deadly implications had forced the World Health Organization (WHO) to declare it as pandemic(3) after declaring it as public health emergency of international concern (PHEIC). This was historic as no other disease outbreak was declared as pandemic since the inception 
WHO in middle of twentieth century. Hardest hit countries include United States of America, India, Brazil, Russian federation,France and United Kingdom. These countries solely account for more than half of the infection around the world(4). The new mutated strain of the coronavirus has been reported from United Kingdom and South Africa(5). It is said to be more virulent than the current strain which is already wreaking havoc all across the globe. Though the recovery rate is as high as 95 percent but the case fatality rate which stands around 3 percent when converted to numbers proved to be in millions. The reason being huge number casualties is attributed to comorbid condition of the infected patient(6). Already underlying medical illness can worsen the COVID-19 infection symptoms outcomes. The preventive measures include lockdown were imposed by various countries and its impact varies according to the country and its contemporary condition. Various studies have been done to check the efficacy of the lockdown. Multispectral impact was seen as lockdown was imposed among which includes behavioral, physical, psychological, economical are prominent ones. In this article, the study on efficacy of lockdowns is compared and a holistic overview has been created so as to arrive at a meaningful conclusion.

\section{NON-PHARMACOLOGICAL INTERVENTIONS (NPI) IN COVID-19} At the advent of the COVID-19 or the coronavirus disease 2019, the novelty of the coronavirus was extremely surprising and researchers were finding it difficult to predict any behavior of the virus. After the World Health Organization (WHO) declared COVID-19 as a pandemic various governmental agency started to feel the severity of the disease spread. They also started to impose some mitigation measures. They include medical and nonmedical interventions. Medical intervention included testing of patients having international travel history, treating it into a COVID-19 care facility and tracing other primary contact so the patient and treating or isolating them too. But medical interventions requires huge money and men resource power which is already lacking(7). So governmental agencies started or impose lockdown and physical distancing to restrict the spread of the virus. Blanket measures like lockdown and physical distancing curbed the spread of the infection but it was not sustainable as the lives versus livelihood debate was started to gaining ground. It also contained the infection numbers for a while and gave the chance to governing authorities to ramp up the medical intervention facilities that needs to be rectified. Varying degree of lockdown was imposed in different countries. Some imposed daylight curfew, some allowed one citizen from each household at a time and some imposed harsher lockdown by not allowing any citizens and competent authorities were deployed on the field with proper precaution in order to fulfill the basic needs of the people under home confinement(8).

\section{LOCKDOWN IMPLEMENTATION AND ITS EFFICACY}

The lockdown as a containment measure was adopted by various countries and by various ways according to respective governing model. Some model were liberal and slightly free others were stricter and harsh as compared to others. It was also influence by the arrival of the viral spread and number of cases. The initiation of the viral spread was started in Wuhan city of the Hubei province of china. Therefore, they were naturally the first responders and started the measure of the lockdown. The spurt of cases in china was seen in early December of 2019 and since then various measures were culminated to city wide and province wise imposition of lockdown. The nature of lockdown in china was 
harsher and stricter. Armed forces were used to observe strict following of the guidelines issued during the outbreak turned epidemic. No meeting was allowed with the infected person admitted to the hospital to family members and if the patient becomes dead then according to the guidelines the family members were not allowed to cremate the deceased patient and authorities were directed to do so on behalf of the patient to avert the viral spread. Although the harsh nature of the lockdown was criticized but it was found to be effective along with mass testing and isolation strategy. According to study the lockdown was in different stages in different continents as it was arrived everywhere at different times(9). Starting from China it spread through European countries particularly Italy and Spain which are directly connected with the emerging financial hub of Wuhan with air connectivity and were late in imposing travel restriction to and from Wuhan city where the outbreak started which later became pandemic. The study has reported both statistically significant positive as well as negative impact. Positive impact means that there will be more cases today if the cases reported yesterday also are more. In negative impact it simply means that lockdown imposing countries have fewer new reporting of infection than the countries that are late or not imposing the lockdown restriction. As the news reports from Europe was suggesting that Europe was hit harder than any other continents. Daily positive infected cases were reported and numbered at 75 thousand to 100 thousand and daily case fatalities were touched to 10 thousand on each day indicating the deadly nature of the COVID-19 infection. The reason being such menace is that Europe is densely inhabited continent and large number of people resides in per square mile area as compared to other parts of the world. Also, many countries are there in small area creating free ground for cross border movement for the virus. In Europe the lockdown coefficient is positive pointing towards reporting of the greater number of cases than other countries that did not imposed lockdown. The coefficient remained positive for over 13 days and thereafter it started to be negative indicating the starting of the benefits of the lockdown. After 17 days the cases started to recede exponentially and were lower than the world average of the reporting of the cases. We have to keep in mind that lockdown and spurt of cases in different countries were at different dates and are situated in different geographical areas of the globe. Various model has been used to normalized the results and ensure unbiased conclusion. This study has found that lockdown was effective as a whole but removal of lockdown in haste has washed away the gains made by the lockdown. (Alfa no)

\section{LOCKDOWN RESTRICTIONS AND MOBILITY PATTERNS}

A study was conducted in Italy whichtracked the mobility of the residents through the cell phone signals. As the digital revolution has arrived, the cell phone penetration was highly dominant not only in developing countries but also in developcountries like Italy. Also, the digital tracking of the patients was used as a mitigating measure of the COVID-19 containment, and warn people if they are violating anyrules, infected cases around their vicinity and so on. Same data were used to track the mobility pattern and number of cases and in turn the efficacy of the mitigating measure for COVID-19 that is the lockdown. Although the lockdown was highly a debatable topic socially as well as politically as it violated the freedom of movement right but it was out compulsion and found out to be effective. Thestudyconducted in was mobile tracking as Italy has one of the highest usages of the mobile phones especially smartphone usage. The smartphoneusing pattern also 
changes over the course of time. Along with food, clothing and shelter, the basic needs of humans now smartphones are also attached and is now an inseparable part of the life. The phones are kept extremely close with themselves and are taken wherever they go. It naturally helps in tracking a person and monitoring its activities. Cell phone location has already been in use to warn people of nearby infected hotspots or spurt of COVID-19 cases. Also, it monitors and ha option of self-assessment which makes the burden of healthcare professionals a little less. Also, it has acted as regulating and compliance mechanism and check if anyone is violating the lockdown guidelines. It is found in the study that during the peak infection period and following there was drastic reduction in movement of the people as indicated by the stagnant signals. It is also attributed to the higher degree of compliance about the movement restriction guidelines. Also feared getting contacted byCOVID-19 played an important role in lessening the newly infected case numbers. There can be seen a lag between imposition of lockdown and case number peak. It can possibly be attributed to the incubation period of the virus which generally lasts from two days to fourteen days average rate being 5 days. Also lag generated by the delayed diagnosis and test results also contributed to the delayed peak of case numbers and its numbers at around 5 to 6 days. Also other nonpharmacological intervention like wearing of face masks, personal protective equipment's (PPE) kits and face shield with regular sanitization of hands played a significant role in containment measures.(9)

A study conducted from data emerging from six countries highlights some important implications of lockdown and its perceived as well as actual efficacy. The countries participating in the study were Brazil, Colombia, Germany, Israel, Norway and United States of America.
Various aspects of the human life were affected during movement restrictions and lockdown. One of which was the psychological impact and the fear of contracting the viral infection of the COVID-19. It was found to be clipped by the perceived benefits of the lockdown and faith in the governing and law enforcement agencies. Various campaign and social health slogans and posters were having great impact and people were adopting healthy practices and finding the chance of quitting certain harmfulhabits such as smoking and consumption of liquor. Also, authentic information plays the vital role in situations of social and widespread distress and access to the same can be a challenge. Infodemic as World Health Organization said is the parallel pandemic raging under the medical pandemic. Therefore, getting the right and authentic information in pandemic induced lockdown can relieve stress by much ore margin but site it remains a challenge. Dietary pattern has changes in this pandemic as people shifted to low calorie, less sugar and fat diet as compared to pre lockdown era. Also inculcating the physical activities such as exercise,yoga and meditation were attached to safeguarding oneself from the infection. Exponential growth in hygienic practice like sanitizing hands and maintaining clean surroundings was also due to the virus's fear. The six countries taken for observation was totally different from one another and in outcomes. For example, the hardest hit in initial days , Italy, were more awaken in terms of lock down measures and other restrictions, whereas denial behavior about the deadly nature of the virus was seen in Brazilian governmental authorities and to some extent in United States of America also. Lockdown measures were strictly followed in former country while later two were relaxed on the lockdown as a containment measure. Israel followed a very strict lockdown whereas countries like Brazil,United Statesof America and Italy 
saw closure of the schools and offices but people were allowed to remain outside their residence. The residents in all the six countries were perceiving different opinions on efficacy, fear of contracting the COVID-19 infection. This was highly dependent upon visible measures like schools, hospitals and worship place closures, widespread information and guidelines dissemination programs and government to citizen communication. These factors had huge impact over behavioral, psychological and cultural outcomes post lockdown. As the governments started to engage in such activities more, the people were feeling more secure and less socially distress.(10)

North American and European countries showed different result from a study conducted in seven countries from these two continents. The countries involved were, Germany,Spain, United Kingdom, Italy, France Sweden and United States of America. There was stark decline in case fatality rate when strict lockdown was imposed and coupling it with widespread testing by Reverse transcript polymerase chain reaction (RT-PCR) test kit as it is considered as the final and the golden standard in diagnosis of the COVID-19 infection. But mutated strains of the coronaviruses were also registered arising the need of more study in to the fact to establish any correlation.(11)

Another study conducted in 27 countries across 7 continents according to the date of lockdown was conducted as these countries imposed the lockdown more or less in the same period of the march 2020. The study culminated in the finding that after 15 days of lockdown there was start in the decline in number of COVID-19 infection cases. The rate may differ according to the type of lockdown imposed but decline can be seen. But the prevalence among the population and case fatality rate were more or less unchanged. This data was compared to the data that was observed before lockdown was enforced.
Growth factor and mortality rate remained at 1.18 and 1.16 respectively(12).

Another mathematical modelling and observations on datasets from different authentic observing agencies showed that any one non-pharmacological intervention (NPI) was not sufficient in the mitigation measures. The study spans in the month of March and April 2020 due to highly congruent period of enforcing various containment measures. All eggs in one basket approach are not efficient in the large-scale disease outbreaks like COVID19. Various other NPI's like physical distancing, wearing of masks, selfisolation, regular sanitization was helping the lockdown measures to be more efficient and effective at the ground level. Also, NPI's tailor made and curated according to local contexts like lockdown in hotspots of COVID-19, various other measures limited to the are affected and not imposed on allthe area plus decision of the said measure should be in the hand of local governing body who knows all the aspects whether geographical, economic, social , culturaletc., in and out. Decentralized approach will immensely benefit and maximum desired outcome can be reaped so as to effectively contain the menace of COVID-19.Compliance is the key element in the effective ness of any measure. People are found to be more complying if the measures are not drastic and the outcome of this is desirable by all. Collective impact instead of singular impact of any NPI may produce the best conclusion and provide valuable guidance about various mitigating measure combination(13).

A cross country panel found in a study conducted by it found that lockdown starts to show its efficacy after ten days after imposition as cases starts to decline. Also, countries with lockdown imposed saw reduction in new infection rate as compared to countries who do not imposed one. It can be efficient in reducing the number of COVID-19 infected cases even 
twenty days after imposition provided considerable degree of compliance is observed. Reduction in $\mathrm{R}_{0}$ value (number of infections by already infected person) were also the key result of the study(14).

\section{IMPACT OF LOCKDOWN AS A MITIGATING MEASURE IN COVID- 19}

Multispectral impact of the lockdown as a containment measure was observed in COVID-19. The initial hiccups in designing the containment strategy was resulted in enforcing the lockdown and physical distancing as a containment strategy to buy out some time to strategize about the COVID-19 mitigation. Lockdown was the general reaction among all the countries affected by the pandemic. Its impact include behavioral, psychological, physical, economical aspects and each have its own importance(15). Various hygienic behavior was adopted in lockdown so as to ward off the virus from one'svicinity. Washing and cleaning hand regularly with soap and sanitizer, marinating physical distancing, wearing mask hygiene maintenance, quitting harmful and sinful habits were among the behavioral changes that were seen for good. But several incidences of domestic violence, suicides also marked the negative side of the behavioral impact. Psychological impact was more of negative than positive as people were confined at home artificially and were under widespread social distress constantly hearing negative news. Infodemic(16) that is misinformation pandemic under ongoing medical pandemic was also on rise. Physical activities were reduced and hence the physical capacity of person due to less activity were also reduced. Those who were able to manage the situation and started the micro exercise at home were better, mentally as well as physically. Many studies shed light on effects of lockdown (17-21). Economy washard hit and under complete closure as movement restrictions and lockdown made impossible to run the industry $(22,23)$. Drastic reduction in gross domestic products (GDP) was observed and widespread recession can be seen in coming months. Job losses and loss of income means can have ripple effect on various other sectors.

\section{CONCLUSION}

Studying various analyses from the different datasets about efficacy of the lockdown as the preventive measure during COVID-19 suggests that it helpful in containing the viral spread and reducing the infection case numbers after 10 to 15 days into the lockdown. The reduction can be observed up to 20 to 25 days into the lockdown but vary according to degree of compliance at various geographical measures. But it was also seen that only one NPI cannot be the solution for all the problems instead a wholesome combination of various NPI's like wearing of masks, sanitizing hands regularly may be the right choice to obtain the maximum efficacy. Decentralization is yet another method through which effective outcome can observed along with tailor made approach and curative solution. As the countries are easing up on lockdown a new strain has demanded the lockdown measure again but this time with piecemeal approach according to local condition. Multispectral impacts need to analyzed post lockdown and rectification in future strategy can be done on the basis of results obtained.

\section{REFERENCES}

[1] Coronavirus [Internet]. [cited 2020 Dec 28]. Available from: https://www.who.int/westernpacific/ health-topics/coronavirus

[2] COVID-19 Map [Internet]. Johns Hopkins Coronavirus Resource Center. [cited 2020 Dec 28]. 
Available

from:

https://coronavirus.jhu.edu/map.html

[3] WHO Director-General's opening remarks at the media briefing on COVID-19 - 11 March 2020.pdf.

[4] WHO Coronavirus Disease (COVID19) Dashboard [Internet]. [cited 2020 Dec 28]. Available from: https://covid19.who.int

[5] Wise J. Covid-19: New coronavirus variant is identified in UK. BMJ [Internet]. 2020 Dec 16 [cited 2020 Dec 23];371:m4857. Available from: https://www.bmj.com/content/371/b mj.m4857

[6] Guan W-J, Liang W-H, Zhao Y, Liang H-R, Chen Z-S, Li Y-M, et al. Comorbidity and its impact on 1590 patients with COVID-19 in China: a nationwide analysis. Eur Respir J. 2020;55(5).

[7] Allam M, Cai S, Ganesh S, Venkatesan M, Doodhwala S, Song $\mathrm{Z}$, et al. COVID-19 Diagnostics, Tools, and Prevention. Diagnostics [Internet]. 2020 Jun [cited 2020 Dec 16];10(6):409. Available from: https://www.mdpi.com/20754418/10/6/409

[8] Zhang L, Tao Y, Shen M, Fairley CK, Guo Y. Can self-imposed prevention measures mitigate the COVID-19 epidemic? PLOS Med [Internet]. 2020 Jul 21 [cited 2020 Dec 16];17(7):e1003240. Available from:

https://journals.plos.org/plosmedicin e/article?id=10.1371/journal.pmed. 1 003240

[9] Vinceti M, Filippini T, Rothman KJ, Ferrari F, Goffi A, Maffeis G, et al. Lockdown timing and efficacy in controlling COVID-19 using mobile phone tracking. EClinicalMedicine [Internet]. 2020 Aug 1 [cited 2020 Dec 27];25. Available from: https://www.thelancet.com/journals/e clinm/article/PIIS25895370(20)30201-7/abstract
[10] Haug N, Geyrhofer L, Londei A, Dervic E, Desvars-Larrive A, Loreto $\mathrm{V}$, et al. Ranking the effectiveness of worldwide COVID-19 government interventions. Nat Hum Behav [Internet]. 2020 Dec [cited 2020 Dec 27];4(12):1303-12. Available from: https://www.nature.com/articles/s415 62-020-01009-0

[11] Alfano V, Ercolano S. The Efficacy of Lockdown Against COVID-19: A Cross-Country Panel Analysis. Appl Health Econ Health Policy. 2020 Jun $3 ; 18$.

[12] Who got it right? New LSE research on the effectiveness of lockdowns [Internet]. LSE COVID-19. 2020 [cited 2020 Dec 27]. Available from: https://blogs.lse.ac.uk/covid19/2020/ 09/17/who-got-it-right-new-lseresearch-on-the-effectiveness-oflockdowns/

[13] Pachetti M, Marini B, Giudici F, Benedetti F, Angeletti S, Ciccozzi M, et al. Impact of lockdown on Covid19 case fatality rate and viral mutations spread in 7 countries in Europe and North America. J Transl Med [Internet]. 2020 Sep 2 [cited 2020 Dec 27];18(1):338. Available from:

https://doi.org/10.1186/s12967-02002501-X

[14] Born B, Dietrich A, Müller G. The effectiveness of lockdowns: Learning from the Swedish experience [Internet]. VoxEU.org. 2020 [cited 2020 Dec 27]. Available from: https://voxeu.org/article/effectiveness -lockdowns-learning-swedishexperience

[15] Blake H, Bermingham F, Johnson G, Tabner A. Mitigating the Psychological Impact of COVID-19 on Healthcare Workers: A Digital Learning Package. Int J Environ Res Public Health. 2020 26;17(9).

[16] DushyantBawiskar, Pratik Phansopkar, Ayurva Vilas Gotmare. 
COVID-19 Facets: Pandemics, Curse and Humanity. Int $\mathrm{J}$ Res Pharm Sci [Internet]. 2020 Aug 6 [cited 2020 Oct 17];11(SPL1):385-90. Available from:

https://pharmascope.org/ijrps/article/ view/2731

[17] Muley, P.P., P.A. Muley, and K.A. Meshram. "Effect of COVID-19 Lockdown on Perceived Stress Scale in Medical Students." Indian Journal of Forensic Medicine and Toxicology 14, no. 4 (2020): 642629.

https://doi.org/10.37506/ijfmt.v14i4. 12611.

[18] Nisargandha, M.A., and S. Dadaraoparwe. "Spread of Coronavirus Disease 2019 (COVID19) during the Lockdown in the Indian Population and Preventive Measures." International Journal of Research in Pharmaceutical Sciences 11, no. Special Issue 1 (2020): 32832.

https://doi.org/10.26452/ijrps.v11iSP L1.2721.

[19] Waghmare, A., S. Shrivastava, and S. Date. "Effect of Covid-19 Lockdown in Trauma Cases of Rural India." International Journal of Research in Pharmaceutical Sciences 11, no. Special Issue 1 (2020): 36568.

https://doi.org/10.26452/ijrps.v11iSP L1.2727.

[20] Wanjari, T.N., and G. Sawarkar. "Lockdown Lifestyle: Engaging the Invisible Enemy." International
Journal of Research in Pharmaceutical Sciences 11, no. Special Issue 1 (2020): 491-95. https://doi.org/10.26452/ijrps.v11iSP L1.2836.

[21] Gaidhane, S., N. Khatib, Q.S. Zahiruddin, A. Gaidhane, S. Telrandhe, and P. Godhiwal. "Depression, Anxiety and Stress among the General Population in the Time of COVID-19 Lockdown: A Cross-Sectional Study Protocol." International Journal of Research in Pharmaceutical Sciences 11, no. Special Issue 1 (2020): 360-64. https://doi.org/10.26452/ijrps.v11iSP L1.2726.

[22] Agrawal, D., N. Khara, B. Mundada, N. Bhola, and R. Borle. "COVID-19 and Its Financial Effects on the Dental Fraternity and Health-Care Workers: A Literature Review." International Journal of Research in Pharmaceutical Sciences 11, no. Special Issue 1 (2020): 628-31. https://doi.org/10.26452/ijrps.v11iSP L1.2883.

[23] Budhrani, A.B. "A Review: Coronavirus, Its Types, and Impact of Covid-19 on Global Wealth." International Journal of Research in Pharmaceutical Sciences 11, no. Special Issue 1 (2020): 455-61. https://doi.org/10.26452/ijrps.v11iSP L1.2811. 